\title{
Research on Design Drawing Change Management under Modern Shipbuilding Mode
}

\author{
Tao Wang, Xiaoping Ma
}

\begin{abstract}
In the process of ship design and construction, the change management of design drawings is a difficult point in project design management. Through the analysis of the management status of ship enterprise documents and design drawings, the paper expounds the shortage of ship filing drawings change management at present, and puts forward the system management method of ship design document archiving storage and change transfer in order to ensure the effectiveness, accuracy and timeliness, it provides a useful reference for shipbuilding enterprises to improve the management level of production design.
\end{abstract}

Index Terms - Document management, Design change, System management.

\section{INTRODUCTION}

Drawing design modification is to modify the original design, aiming at improving the existing design, or correcting design errors, or adapting to new design requirements, to ensure the design quality and design feasibility. Ship construction engineering is a complex system engineering with long-term, complex and dynamic characteristics [1]. The fluctuation of various factors in the special production mode of design, production and modification at the same time will cause the change of various factors, so that there are a lot of uncertain factors in the construction process leading to the design change, ship design change has become an indispensable part of construction project management, in addition, drawings change is directly related to cost, planning, safety, quality and so on, the management of drawings change in shipbuilding enterprises is particularly important.

\section{ANALYSIS OF CAUSES AND PROBLEMS OF DRAWING CHANGE}

The reasons for ship design changes are as follows: (1) Shipowner plus account, (2)Perfection of design , (3)Equipment anomalies , (4)Construction quality , (5)Design quality, (6)Relevance of basic, detailed design , (7)Design supplement, (8) Uncontrollable class [2]. According to the participants, it can be summed up as ship owner modification, classification society modification, equipment manufacturer modification, foreign contractor modification, technical department modification and workshop modification, as shown in Figure 1.

XiaoPing MA, Professor, School of Naval Architecture \& Ocean Engineering, Jiangsu University of Science and Technology, Zhenjiang, Jiangsu, China

Tao WANG, School of Naval Architecture \& Ocean Engineering, Jiangsu University of Science and Technology, Zhenjiang, Jiangsu, China

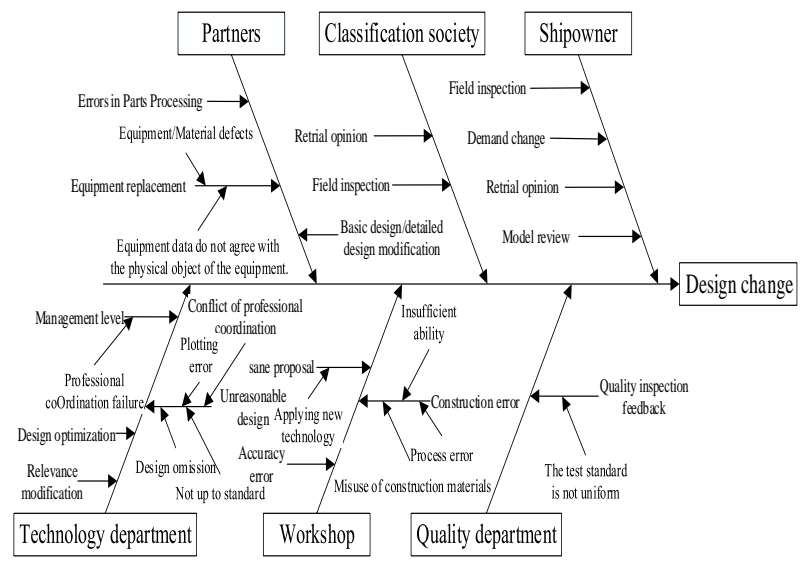

Fig.1 Fishbone Diagram of Design Change Causes

Drawing design changes caused by the above reasons, if there are no effective management means and methods, there will be a series of hidden dangers in document management, for example, the issue of revision of drawing documents: when the original drawings are modified for some reason, how to upgrade the revised version of drawings while ensuring human identification control and system identification, how to ensure that the acquired drawings are the latest version of drawings, how to store and display different versions of drawings, in addition, if the altered drawings can not be shared in time, it will lead to design or construction errors in the downstream stage. High-level management of drawing change should be based on document management, document management should pay attention to the following points: clear document classification structure tree, file status and version updating, document process $\log$, simplified archiving, authority management, fuzzy index query.

\section{MANAGEMENT OF SHIPPING COMPANY-LEVEL DOCUMENTS AND PROJECT-LEVEL DRAWINGS}

The systematic management of drawings in shipbuilding enterprises should be based on the drawings catalogue, which can be divided into two categories: company-level documents and project-level documents, the two management modes need to be differentiated.

\section{A. Management of corporate documents}

Company-level documents mainly refer to department documents stored by non-functional departments and documents not directly related to production stored by functional departments, this kind of document is mainly maintained and managed by the clerk of each department, according to the node level of the document structure tree of the company, the clerk of the Department can only modify the operation at the node level of the department.

The filing of company-level documents is relatively simple, 
the clerk adds directory maintenance of the required uploaded archived drawings to the system in his daily work, all attributes of each directory are displayed in the form of a record (unfiled and archived directories are distinguished by different background colors). Important attributes should include standard number, standard name, English name, national publishing department, implementation date, expiration date, publishing date, page number, version, etc. Some attributes need to be manually maintained and added, some attributes are automatically identified and filled when uploading drawings, such as page number and version, as shown in Table 1

\begin{tabular}{|c|c|c|c|c|c|c|c|c|}
\hline $\begin{array}{l}\text { Standard } \\
\text { number }\end{array}$ & $\begin{array}{l}\text { Standard } \\
\text { name }\end{array}$ & $\begin{array}{l}\text { English } \\
\text { name }\end{array}$ & $\begin{array}{l}\text { Publishing } \\
\text { department }\end{array}$ & $\begin{array}{c}\text { Date of } \\
\text { implementation }\end{array}$ & $\begin{array}{c}\text { Date of } \\
\text { annulment }\end{array}$ & $\begin{array}{l}\text { Date of } \\
\text { release }\end{array}$ & $\begin{array}{l}\text { pages } \\
\text { Number }\end{array}$ & Edition \\
\hline $\begin{array}{c}\text { Manual } \\
\text { maintenance }\end{array}$ & $\begin{array}{c}\text { Manual } \\
\text { maintenance }\end{array}$ & $\begin{array}{c}\text { Manual } \\
\text { maintenance }\end{array}$ & $\begin{array}{c}\text { Manual } \\
\text { maintenance }\end{array}$ & $\begin{array}{c}\text { Manual } \\
\text { maintenance }\end{array}$ & $\begin{array}{c}\text { Manual } \\
\text { maintenance }\end{array}$ & $\begin{array}{c}\text { Manual } \\
\text { maintenance }\end{array}$ & $\begin{array}{l}\text { Automatic } \\
\text { fill }\end{array}$ & $\begin{array}{l}\text { Automatic } \\
\text { fill }\end{array}$ \\
\hline
\end{tabular}

The directory is added by manual input or Excel template import or copy and paste, and other human-computer interaction methods to improve user experience, on the other hand, users can directly improve their work efficiency by selecting methods according to their needs, after adding the catalog to the system, the document can be uploaded and stored by one key directly through the right-click function, documents can automatically find the path archiving according to the document number matching standard number (the document name needs to contain the standard number to successfully match the archiving), for documents with attachments, they can also be archived under this catalog through attachment management, but they are managed differently.

The company documents should pay attention to the sharing and timeliness of the documents, when the online documents change, the drawings are archived again in the original drawings catalogue, the system records the archiving time, archivists and versions, the original drawings are stored as historical data, when the document acquirers view or download the documents, they can clearly get the latest information of the documents.

\section{B. Project-level Document Management}

Project-level document management is different from company-level document management, the former has many hierarchical partitions of node levels, large amount of additional attribute information and strong logic, additionally, additional attribute information will be added to the process of drawing management, in order to improve the management level and transmission efficiency of subsequent design drawings, it is particularly important to straighten out the relationship between field attributes.

Project-level document management is project-based management, document catalogue is maintained by project technical document control, catalogue information should include document number, Chinese name, English name, drawing type, version, responsible person, design stage, secret level, specialty, compilation unit, start date, end date, related PBS information, page number, A0, A1, A2, A3, A4, archiving date, archiving person, archiving manual, number, total printing times, current version printing times, current version printing date, number of attachments, version status information, notes. The above information is maintained by the project technical document control to the system, in which the number of pages, maps, archiving date, archivist, archiving manual number, total printing times, current version printing times, current version printing date, attachment number, version status information are automatically filled after subsequent archiving or printing, drawing catalogue and PBS are linked to clearly show the drawing progress based on subsection/system/area drawings.

Project-level document archiving is divided into one-key archiving and design process archiving according to the business needs of shipbuilding industry, one-key archiving refers to uploading project document control directly to the system without approval process, for example, the archiving of drawings for retrial, the archiving of design process refers to the archiving of design drawings after approval process. One-key archiving is the same as the one-key archiving of company-level document management without detailed description, the design process archive is shown in Figure 2.

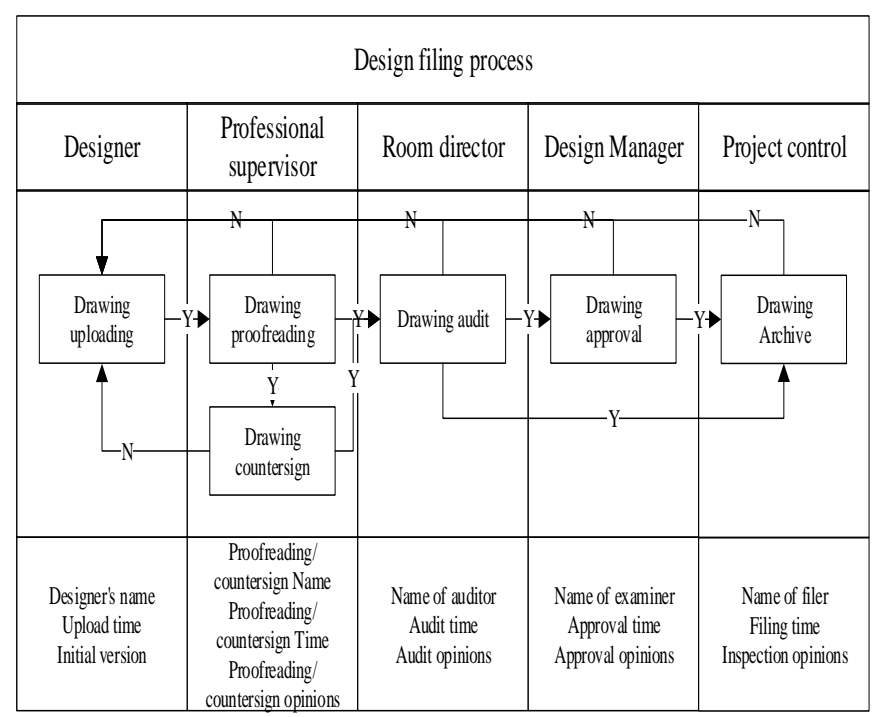

Fig.2 Design Filing Flow Chart

Through investigation and analysis, it is found that in order to improve the management level of drawing archiving system, the following points should be paid attention to: 1)Process diversification: Designers can pre-set approval paths and approvers at each step according to the classification of drawings, and can set up multiple process configurations to reach different process configurations corresponding to different projects, which is in line with the business scenario of project designers in ship enterprises participating in multiple projects.(2)Possessing reversible operation: Oneself find errors in time after completing the task and send them to the same level of approver before I withdraw them (if the next operation is in the state of pending processing), or if the next operation is not approved on time by the operator, the operation should be sent to the same level 
International Journal of Engineering and Applied Sciences (IJEAS)

ISSN: 2394-3661, Volume-6, Issue-4, April 2019

of approver for approval before withdrawing. (3) Optimizing the effect of map reading: task message is pushed in time, the receiver is reminded to view the task accurately, and the system shows the most concerned information to the approver through a concise interface when viewing the post-processing task of process log, it can input the view in real time and add screenshots and annotations to improve the efficiency of map reviewing as a whole.(4)Optimized version management: Drawing version is divided into system version and manual version, each time the archiving system version of the same drawing is upgraded automatically, such as 0 version upgraded to 1 version, and so on. Artificial version is controlled by the designer when uploading drawings, such as $A$ version can be directly changed to $C$ version. Original drawings are still stored in the same catalogue, view/download the catalogue drawings and open new ones by default, old version drawings can also be selected.5CControllable process: Project document control can directly intervene in the process, can act as an agent to examine and approve human rights, restore the stagnant process, and can revoke the archived drawings, timely maintenance of smooth process.

The storage of drawings with the drawing catalogue as the management object and the above functions can not only enlarge a large amount of manpower and material resources, but also lay the foundation for subsequent design drawings changes.

\section{ShIP DraWIng Change Management}

Drawing change management is based on project-level drawing management, the task of drawing change management is to control and manage department personnel, change process and drawing information and their relationships [3], as shown in Figure 3, how to ensure the timeliness, accuracy and sharing of drawing changes is the difficulty of change management.

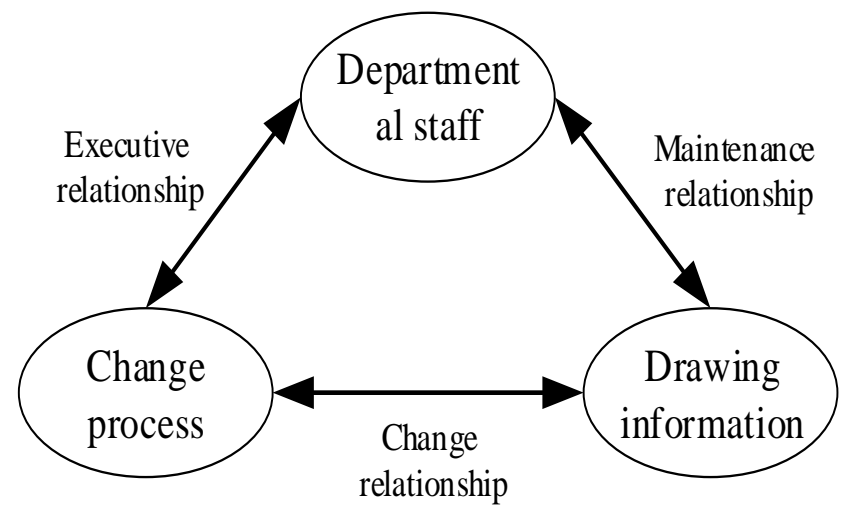

Fig.3 Three Elements Diagram

The key point of system management drawings change is not the process, but the interaction efficiency between personnel and drawings information, that is, how to upload the revised content of drawings quickly, accurately and completely, and how to get clear and complete change information and revised content quickly by approver, and how to improve the software platform will play a vital role, there is no big difference between the filing process of modifying drawings and the filing process of designing drawings. The process is shown in Figure 4.

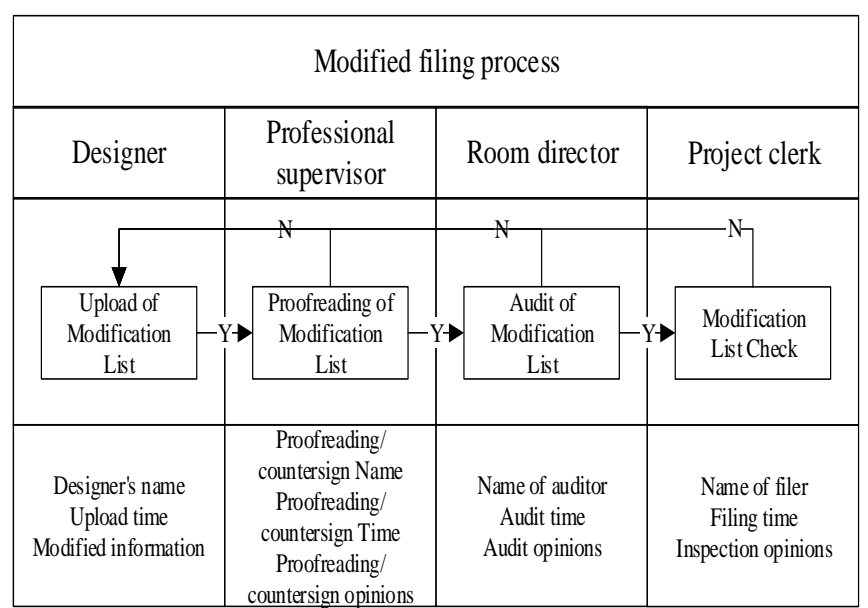

Fig.4 Modified Single Filing Flow Chart

How to improve the efficiency of information interaction between personnel and drawings through the system, different roles pay different attention to the key points. (1)Application: In the application interface of the designer to create a revision form, the only revision form number is defined first, and the revision list number is related to the revised project engineering, that is, which item is the revision of the revision form, and the type of the revision form is determined. The path of subsequent archiving is based on the type of the revision form, which is filed under the directory of the corresponding professional revision form, and then upload the revision drawing related to the original map catalogue (Filtering the revised drawing catalogue). When correlating the original drawing, the following information should be added: modifying working hours, modifying reasons, construction status, description of reasons, information of material change (Excel import), whether the original drawing is upgraded, and operation information of adding, deleting, replacing, inserting and replacing the whole drawing. The schematic diagram of page change is shown in Figure 5.
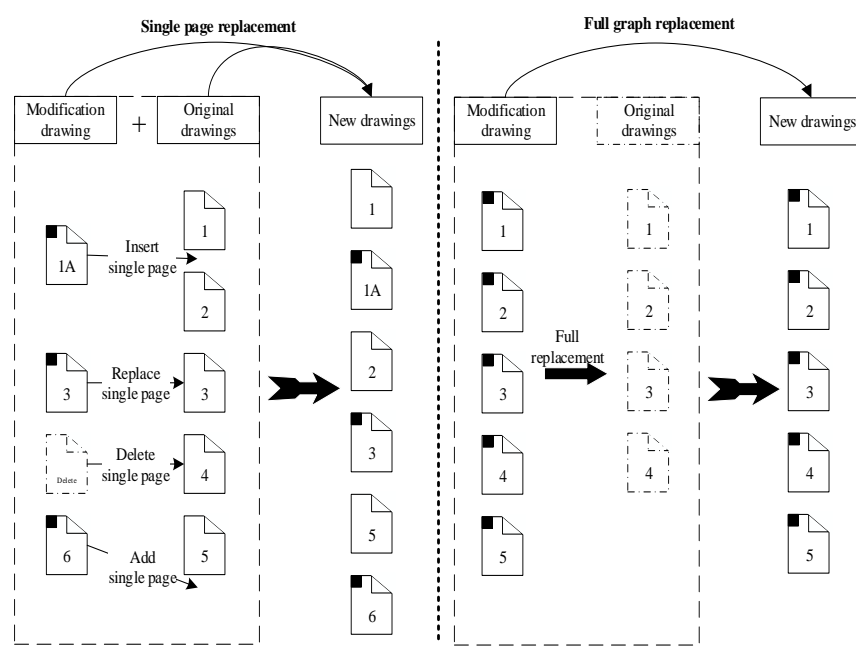

Fig.5 Page File Change Diagram

Because there is a reason for modifying the business background of a shipping enterprise to correspond to multiple drawings, or multiple reasons to correspond to multiple drawings, or even multiple reasons to correspond to one drawings, it is necessary to correlate the original drawings with a certain dimension, according to the practical experience on the spot, this paper chooses the reason 
dimension to correlate the original map, that is to say, multiple original maps can be correlated under one modified reason, if multiple reasons modify a drawing, label it in the first reason association, other reasons only need to correlate the original map without adding, deleting and inserting, when adding, deleting, replacing and inserting related original drawings, the number of pages of original drawings and corresponding revisions should be previewed at the same time, after operation, the comparison before and after changes should be displayed in real time so as to facilitate designers to locate quickly and replace accurately and improve work efficiency, after the information input is completed, the system automatically generates the modified sheet cover in predefined format according to the input information and operation records, the designer can quickly check the whole input information through the cover, and save time for subsequent examination and approval, finally, the designer submits an application and the application flows downward according to the established process configuration.

(2)Approval: Proofreading and auditing are collectively referred to as approval steps, After the approver receives the task push, he first checks the process log, which shows the process path and the approver, approval time, approval action (consent/rejection), approval opinions at each step, he can clearly understand the origin and development of this task in the first time, and then deals with this task, the approver pays most attention to two points, first, which modification sheets have been modified, and second, how to modify them, the first problem is solved by automatically generating the modification sheet cover, the examiner can understand what the modification sheet has changed by looking at the modification sheet cover, and highlight the modification pages in the pages of the original drawing after modification, after positioning the pages, the revised drawings, the revised drawings and the difference drawings are previewed by synchronous zooming and contrast preview (the difference drawings are the drawings before and after modification that are compared to generate the drawings with different color lines showing the deleted lines and the newly added lines). The comparison effect drawings are shown in Figure 6, When reading drawings, real-time intercept annotations can be added to the opinion bar to accurately convey their approval opinions, this method can successfully solve the second problem, the solution of the above problems can greatly save the examiner's energy and time, greatly reduce the approval time and improve the efficiency of map reading.
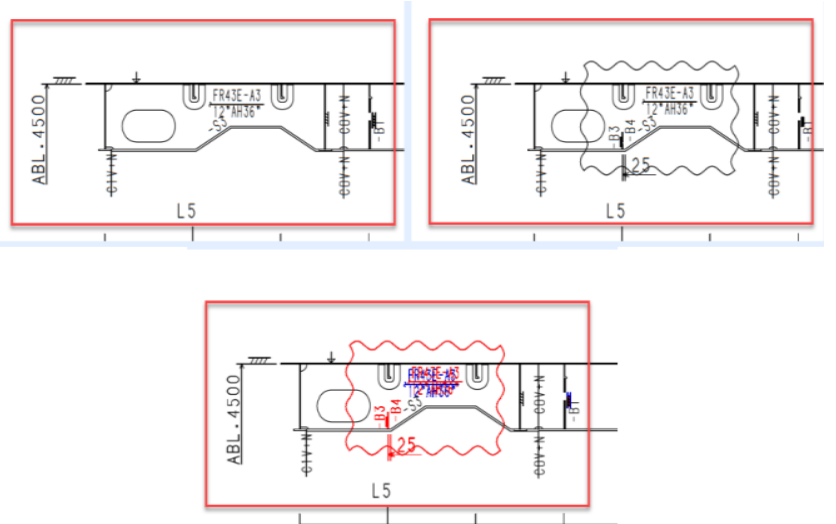

Fig.6 Comparisons before and after modification
(3) Standard inspection and archiving: Through standardized input of designers and automatic summary of records generated form, a series of items can be avoided, there are few items needed for project document control and standard inspection, the time of document control and drawing is greatly reduced, and there is no link of modifying single card in archiving, after filing, the revision sheet is stored separately from the new drawing, the new drawing is still filed in the original drawing catalogue, the system covers the upgrade, the revised sheet cover and the revised drawing are stored as the revision sheet to the corresponding professional revision, the two are queried separately after filing.

Note: In the interface of inquiry, the latest status of drawings can be accurately transmitted to the drawings acquisition party by distinguishing the unfiled, filed, filed and modified drawings catalogues with different background colors.

\section{CONCLUSION}

Drawing as the basis of site construction, it is necessary to strengthen the management of drawing change, this paper takes the reasons of design change as the background, points out the inevitability of change, and provides a management method of drawing system based on drawing catalogue, it also points out the key points of drawing change based on good drawing management: the interaction efficiency between personnel and drawing information, the system management methods from the perspective of applicants, approvers and archivists to improve efficiency, and the subsequent submission of rejection opinions, design tasks and design plans on the basis of drawing management will form a complete design engineering management system, in summary, the system management method will help to improve the design management level of shipbuilding enterprises.

\section{REFERENCES}

[1] Zhang Faguang, Liu Yujun , Ji Zhuoshang. Simulation and Optimization of Ship Sectional Construction Plan [J]. Computer Integrated Manufacturing System , 2011, 17(12): 2643-2651.

[2] Pan Yanhua, Sun Diwen. Analysis of the Impact of Design Change on Material Cost in Ship Construction[J]. Ship Engineering, 2016, 38(06): 88-92.

[3] Liu Huaqing, Wan Li, Zhong Yifang. Analysis and Research on Engineering Change Management [J]. Computer Integrated Manufacturing System -CIMS, 2000(06):31-36.

XiaoPing MA, Professor, School of Naval Architecture \& Ocean Engineering, Jiangsu University of Science and Technology, Zhenjiang, Jiangsu, China

Tao WANG, School of Naval Architecture \& Ocean Engineering, Jiangsu University of Science and Technology, Zhenjiang, Jiangsu, China 